\title{
Influence of emulsifiers on the characteristics of polyurethane structures used as drug carrier
}

\author{
Alina Heghes ${ }^{1}$, Codruta M Soica', Simona Ardelean², Rita Ambrus ${ }^{3}$, Danina Muntean ${ }^{4}$, Atena Galuscan \\ Dan Dragos ${ }^{1}$, Daniela Ionescu ${ }^{1 *}$ and Florin Borcan ${ }^{1 *}$
}

\begin{abstract}
Background: Emulsifiers have a significant role in the emulsion polymerization by reducing the interfacial tension thus increasing the stability of colloidal dispersions of polymer nanostructures. This study evaluates the impact of four emulsifiers on the characteristics of polyurethane hollow structures used as drug delivery system.

Results: Polyurethane (PU) structures with high stability and sizes ranging from nano- to micro-scale were obtained by interfacial polyaddition combined with spontaneous emulsification. The $\mathrm{pH}$ of PU aqueous solutions $(0.1 \% \mathrm{w} / \mathrm{w})$ was slightly acidic, which is acceptable for products intended to be used on human skin. Agglomerated structures with irregular shapes were observed by scanning electron microscopy. The synthesized structures have melting points between $245-265^{\circ} \mathrm{C}$ and reveal promising results in different evaluations (TEWL, mexametry) on murine skin.

Conclusions: In this study hollow PU structures of reduced noxiousness were synthesized, their size and stability being influenced by emulsifiers. Such structures could be used in the pharmaceutical field as future drug delivery systems.
\end{abstract}

Keywords: Hollow structures, Polyurethane, Hexamethylene diisocyanate, Zeta potential, TEWL, Mexameter

\section{Background}

Several varieties of structures (polymeric and metal nano- and micro-particles, liposomes, micelles, quantum dots, dendrimers, lipoproteins, nanotubs) were used as drug carriers in order to reduce drug metabolism, drug toxicity and to prolong in vivo drug activity [1]. The liver isoenzymes known as cytochrome P450 are involved in phase I of drug metabolism [2]. During a study of drug elimination pathways it was established that the cytochrome $\mathrm{P} 450$ is responsible for complete removal from the human body of more than a half of 400 drugs marketed in Europe and US [3]. Toxicity studies for polymermethotrexate conjugate vs. free methotrexate on murine rheumatoid arthritis model indicate that the free compound starts to cause animals'death at the maximum tolerated dose and is highly toxic at LD50 level, while the polymermethotrexate conjugate shows no toxicity at the same equivalent concentrations [4]. The drug carriers can prolong the in vivo drug activity, both by their controlled drug-

\footnotetext{
* Correspondence: ionescu.daniela@umft.ro; fborcan@umft.ro

${ }^{1}$ Faculty of Pharmacy, "Victor Babes", University of Medicine and Pharmacy

Timisoara, 2nd E. Murgu Sq, Timisoara 300041, Romania

Full list of author information is available at the end of the article
}

release technology and a long-lasting target binding and rebinding mechanism [5].

Polyurethanes are commonly used in medical applications and their use continues to expand due to their versatility, biocompatibility and hemocompatibility. There are several types of PU, including the following: liquid PU for hollow-fiber devices, PU for dip-molding, PU coatings, biostable PU and thermoplastic PU [6]. Sivak WN [7] synthesized a novel PU drug delivery system based on lysine diisocyanate and glycerol using various tertiary amines and organometallic urethane as catalysts. The use of LDI-glycerol PU foams as drug carriers for the controlled release of 7-tert-butyldimethylsilyl-10-hydroxycamptothecin (DB-67) revealed that such foams were capable of delivering therapeutic concentrations of DB-67 in vitro over an 11 weeks trial period [8].

The purpose of the present investigation was to develop aliphatic PU structures with a diameter in the range of $100-300 \mathrm{~nm}$ in the absence of a catalyst. We also studied the effect of four emulsifiers on the structures' size and stability and also their noxiousness on murine skin model.
(C) Chemistry Central

( 2013 Heghes et al.; licensee Chemistry Central Ltd. This is an Open Access article distributed under the terms of the Creative Commons Attribution License (http://creativecommons.org/licenses/by/2.0), which permits unrestricted use, distribution, and reproduction in any medium, provided the original work is properly cited. 


\section{Results and discussion}

The development of novel targeted nano-polymers in the drug delivery field is currently a research topic of high interest $[9,10]$. In our research the main aim was to avoid the potentially toxic additional raw materials. Only aliphatic compounds were used even if it is well-known that these compounds lead to final products of poor physical and mechanical properties [11]. In this synthesis the presence of a chains' initiator was not necessary and the reaction went without catalyst. Unlike previous studies [12] a single surfactant has been used instead of a mixture (lipophilic or hydrophilic) and only in a small amount.

The $\mathrm{pH}$ values of $\mathrm{PU}$ solutions were determined using a Schott TitroLine at $25^{\circ} \mathrm{C}$ as described in the literature [13]. The measurements were made in triplicate and data were expressed as mean and standard deviation. The obtained samples show slightly acidic $\mathrm{pH}$ values $(5.88 \pm 0.11$ for sample PuS-1, $6.07 \pm 0.09$ for sample PuS-2, $5.98 \pm 0.16$ for PuS-3 and $6.24 \pm 0.09$ for sample PuS-4). The above $\mathrm{pH}$ values are appropriate for products intended for skin application considering that skin $\mathrm{pH}$ is around 5.80 for men and around 5.54 for women [14]. Variable skin $\mathrm{pH}$ values were reported in the literature, all in the acidic domain, but varying from 4.0 to 7.0 depending on the purpose of using [15]. These slightly acidic solutions are acceptable for dermal applications because they do not cause dry skin as a regular soap does and also maintain the normal skin microflora.

The results obtained by using Zetasizer Nano ZS indicate that PU structures are relatively homogeneous and their size ranges from nano- to micro-scale (Table 1). The increase of the emulsifier amount would most probably reduce the structures' size below $100 \mathrm{~nm}$ (the limit between the two scales) because emulsifiers produce lower interfacial tension and increase the stability of colloidal dispersions, therefore avoiding aggregates' formation.

Zeta potential values are used to predict particles' stability, stable particles presenting a zeta potential more negative than $-30 \mathrm{mV}$ or more positive than $+30 \mathrm{mV}$ [16]. All this considered, the PU structures obtained in the first two experiments (using Cremophor EL and Cremophor A6 as emulsifiers) are considered the most stable products.

The presence of macromolecular aggregates with irregular shapes was noticed using scanning electron microscopy (SEM). Irregular amorphous-crystalline nature of the samples can also be seen in SEM images (Figures 1, 2,
3, 4). The non-spherical shape of the PU structures affect their flowing properties and might also influence their targeting ability [17]. SEM pictures revealed a non-porous material which represents an advantage for a drug carrier in terms of protection of its load. Non-agglomerated structures cannot be successfully synthesized probably due to the small amount of emulsifier which affects the structures' stability and tendency to pack [18].

At the glass transition temperature, $\mathrm{Tg}$, the molecules have enough energy to partially overcome the intermolecular forces, and have more freedom of movement [19]. The presence of the PU structures glass transition is noticed on the DSC curves around $65^{\circ} \mathrm{C}$, which reveals the predominant crystalline nature of the polymer [20]. A crystallization exothermic peak $(+124.5 \mathrm{~mJ})$ was recorded at $193.74^{\circ} \mathrm{C}$ in the case of PuS-4 sample. Further heating above the crystallization temperature results in an endothermic peak which corresponds to the melting of the crystalline region [21]. The melting points of the synthesized $\mathrm{PU}$ structures were between $245-265^{\circ} \mathrm{C}$ (Figures 5, 6). The thermal behaviour survey of the obtained PU structures has revealed that Cremophor-type emulsifiers did not significantly influence the melting process.

TEWL was measured using a non-invasive procedure in order to detect any skin barrier disorder. In the first day of the experiment, all mice exhibited TEWL values between $0-10 \mathrm{~g} / \mathrm{h} / \mathrm{m}^{2}$, which is the specific range for a healthy skin, values that were used as reference [22]. No significant differences were noticed between animal groups or between the first and last day of the experiment (Figure 7). The best results were obtained in case of the mice treated with PuS-1 and PuS-2 creams (TEWL differences below $3 \mathrm{~g} / \mathrm{h} / \mathrm{m}^{2}$ in 30 days, values which were also recorded in the case of blank cream application).

Found in the basal layer of the epidermis, melanocytes produce melanin which determines skin colour [23]. Studies concerning the melanin content of nude mice skin were developed in order to establish the human malignant melanomas' progress [24], radioimmunotherapy efficacy against experimental human metastatic melanoma [25] or the effect of skin pigmentation in bioluminescent imaging [26]. It is well-known that skin often reacts to external agents by modifying the constitutive pigmentation pattern [27]. In this study, the melanin content was investigated using mice skin, which presents extremely close values

Table 1 The PU structures characteristics obtained by Zetasizer Nano ZS

\begin{tabular}{|c|c|c|c|c|}
\hline \multirow{2}{*}{$\begin{array}{l}\text { Sample } \\
\text { code }\end{array}$} & \multirow[t]{2}{*}{ Emulsifier } & \multicolumn{2}{|c|}{ Particle size (nm) } & \multirow{2}{*}{$\begin{array}{c}\text { Zeta potential } \\
(\mathrm{mV}) \text { mean } \pm S D\end{array}$} \\
\hline & & Mean \pm SD & Polydispersity index & \\
\hline PuS-1 & Cremophor EL & $164 \pm 12$ & 0.2 & $33.9 \pm 5.0$ \\
\hline PuS-2 & Cremophor A6 & $201 \pm 19$ & 0.5 & $37.5 \pm 4.4$ \\
\hline PuS-3 & Cremophor A25 & $298 \pm 11$ & 0.4 & $23.0 \pm 4.8$ \\
\hline PuS-4 & Cremophor RH40 & $379 \pm 23$ & 0.3 & $29.7 \pm 3.1$ \\
\hline
\end{tabular}




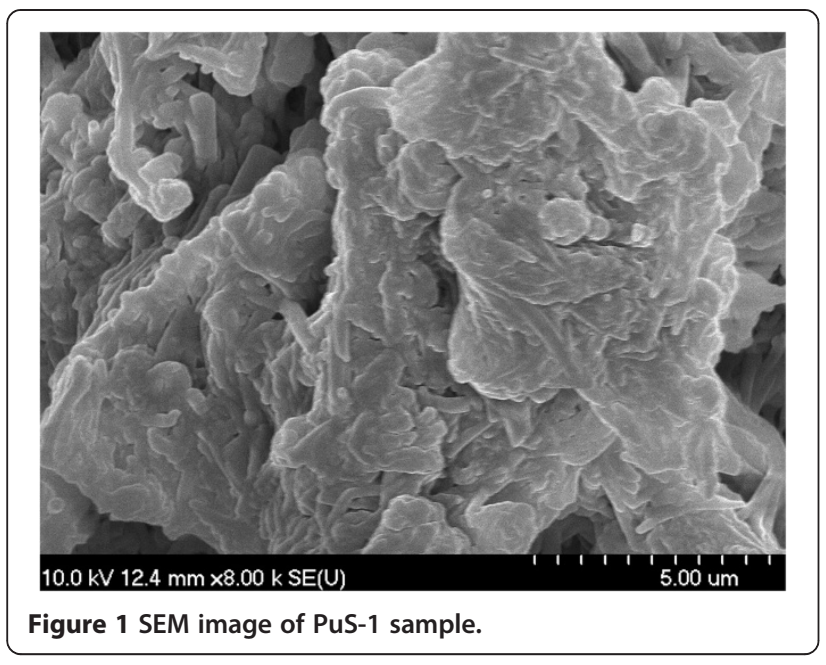

(maximum range of variation was 10 melanin arb. units in the first day of the experiment). The melanin evolution (Figure 8) presents an increase for all mice (whether they were treated with blank cream or cream with PU structures); it is pertinent to mention that in the case of mice treated with PuS-1 and PuS-2 creams the increase of melanin content was not so pronounced.

Erythema (redness of the skin) caused by expansion and congestion of the capillaries is usually a sign of inflammation or infection [28]. Irritant compounds such as surfactants have been extensively studied in the last decade and it has been noticed that erythema values can be correlated with their irritation potential [29]. In this experiment, the lowest change of the erythema (local haemoglobin) values was noticed in case of the mice treated with blank cream and PuS-2 cream respectively, which recommends the latter as the transdermal carrier with the lowest toxicity (Figure 9).

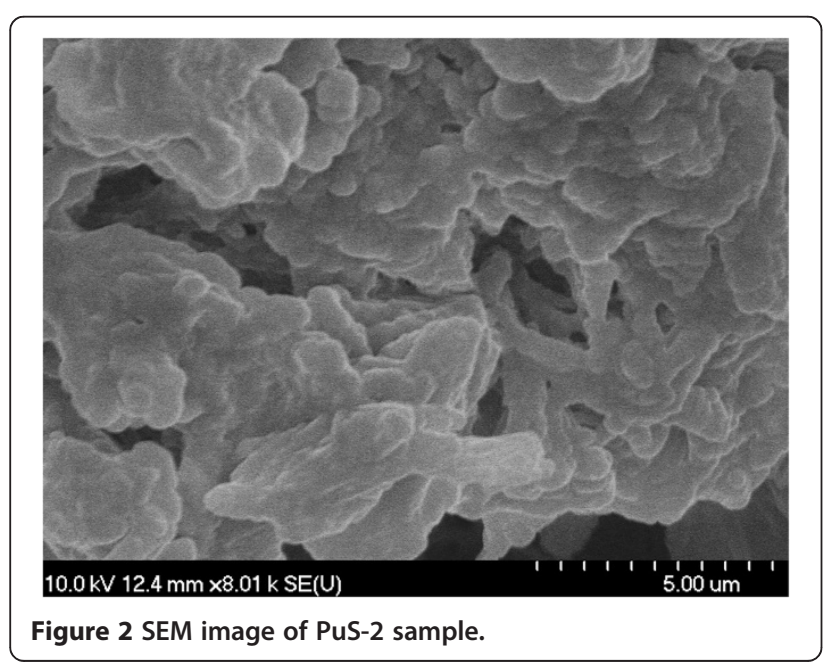

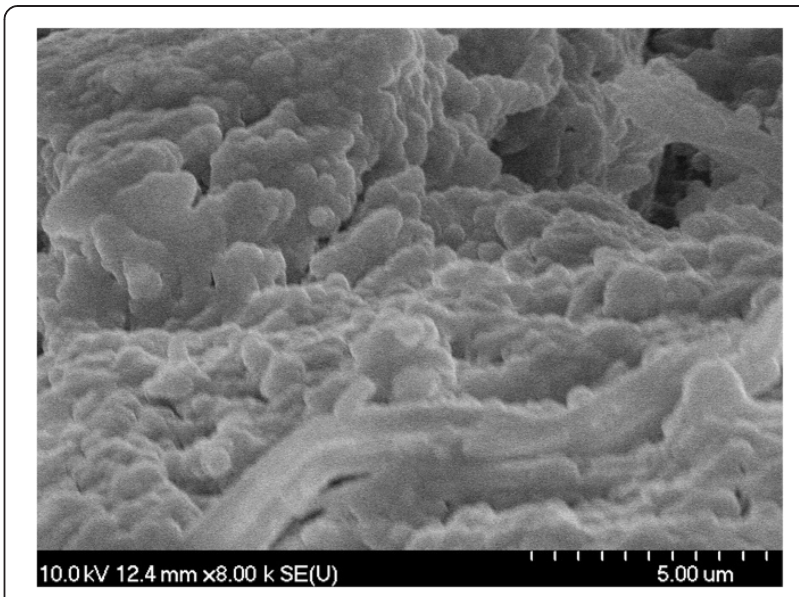

Figure 3 SEM image of PuS-3 sample.

\section{Conclusions}

In this research PU structures were synthesized using a well-known procedure, the interfacial polyaddition combined with spontaneous emulsification. HMDI in acetone was used as isocyanate component and a mixture of MEG, 1,4-BD and PEG 200 in water was used as hydroxylic component. Four different emulsifiers were used and the synthesis was done without any chain initiator or catalyst. The PU structures showed a good stability, melting points between 245$265^{\circ} \mathrm{C}$, and sizes between $150-400 \mathrm{~nm}$. The PU structures were embedded in a cream for topical applications on murine skin. Evolution of TEWL, melanin content and skin erythema were recorded for a period of 30 days. The comparative analysis revealed that PU structures based on Cremophor A6 present the best toxicological profile and can be used as drug carriers for therapeutic purposes.

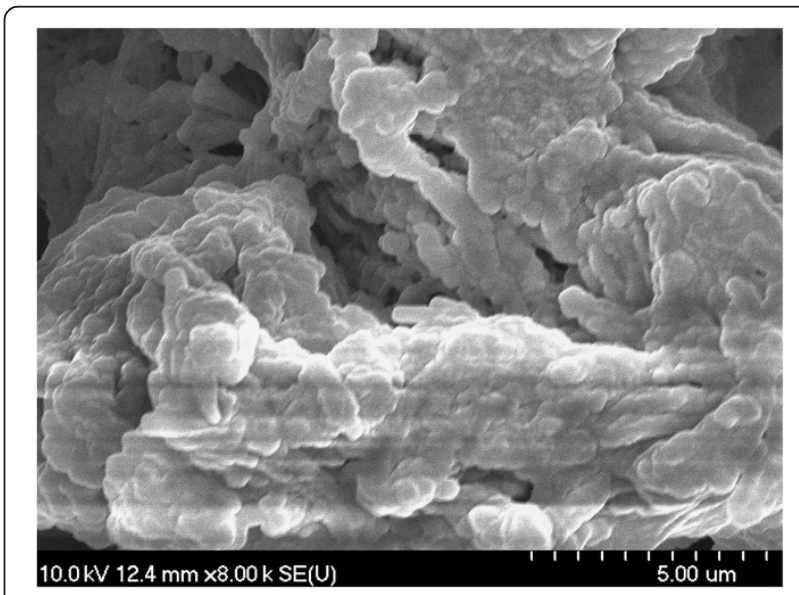

Figure 4 SEM image of PuS-4 sample. 


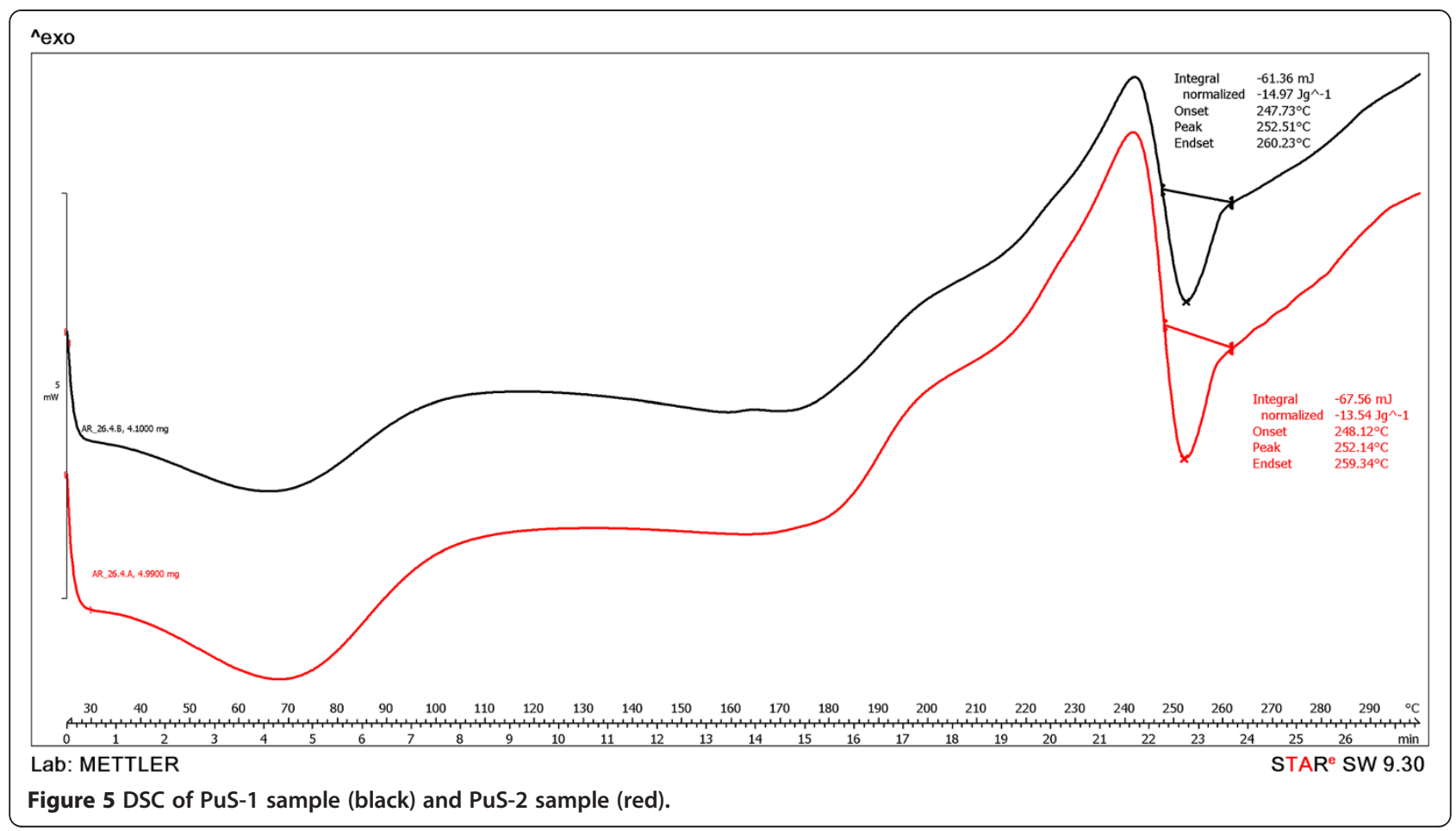

\section{Methods}

\section{Raw materials}

Hexamethylene diisocyanate (HMDI), polyethylene glycol (PEG 200) and acetone were obtained from Merck (Germany). Emulsifiers (Cremophor EL, Cremophor A6, Cremophor A25, and Cremophor RH40) were kindly donated by our colleagues from University of Szeged (Hungary). Mono-ethylene glycol (MEG) was purchased from Lach-Ner s.r.o. (Czech Rep.) while 1,4-butanediol (1,4-BD) was purchased from Carl Roth GmbH (Germany). All substances were used as received.

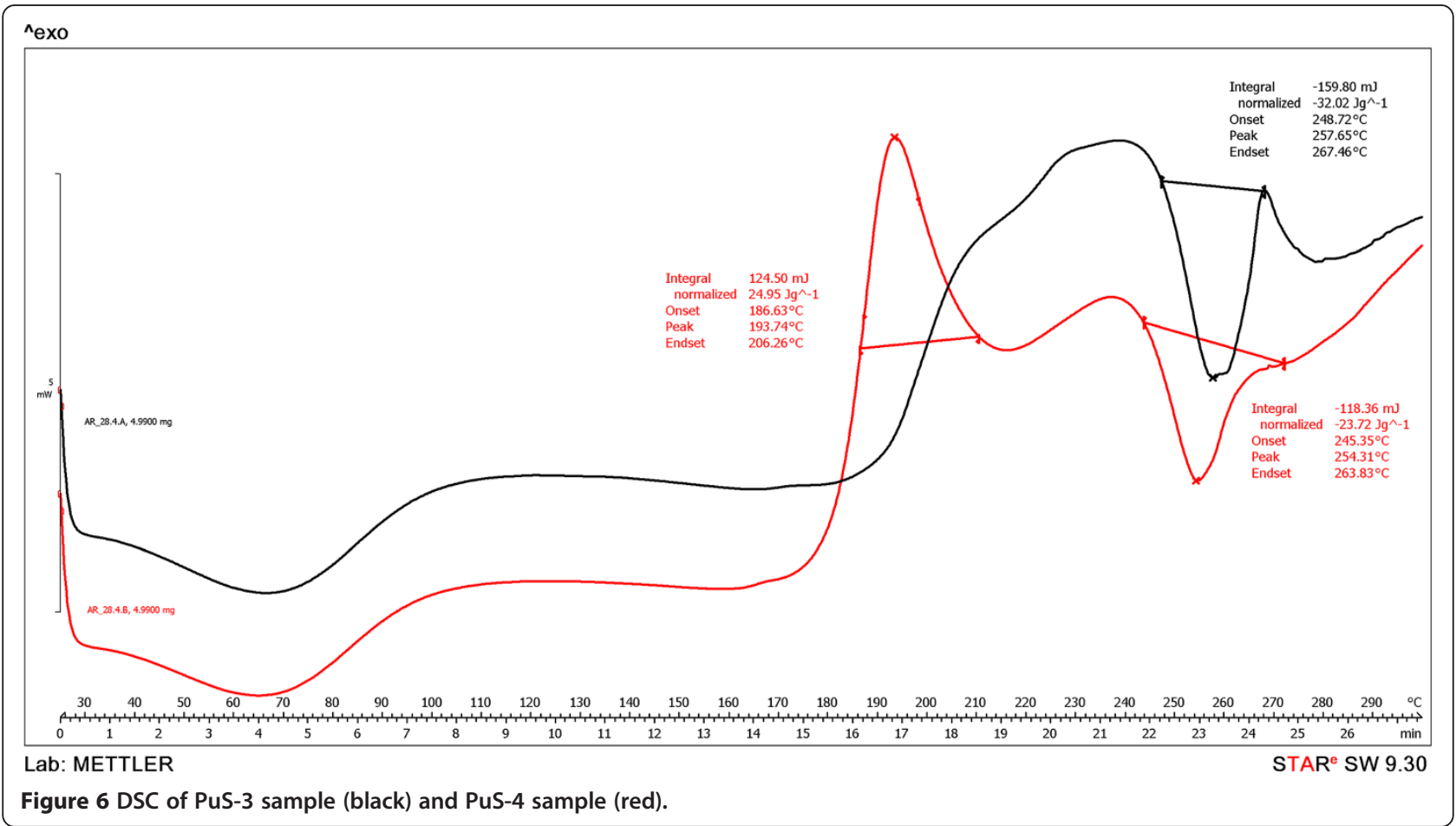




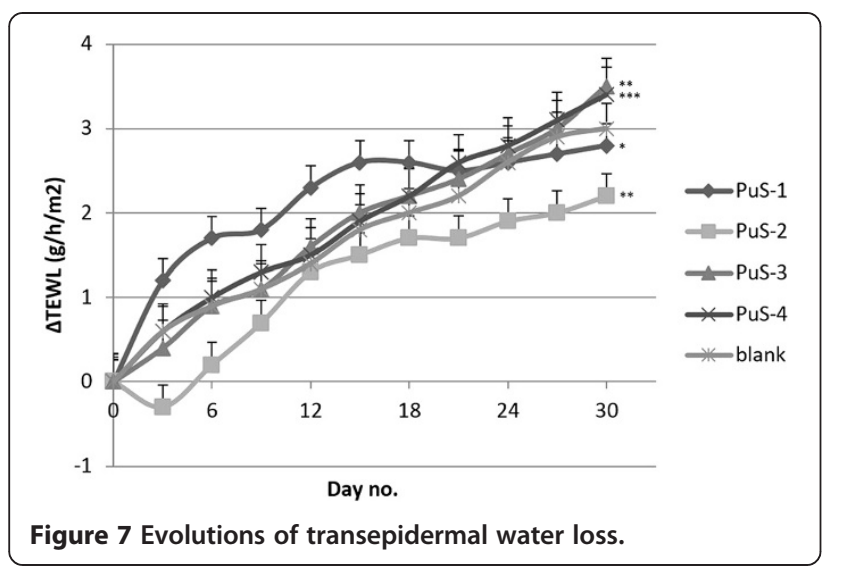

Synthesis protocol

The influence of the aqueous components ratio [30], isocyanate component [31], and influence of stirring speed [32] were already studied by our team in order to optimize the structures sizes and stability.

The polyaddition reaction between HMDI and diolpolyether mixture for the PU structures synthesis follows the reaction from Figure 10.

Isocyanate and hydroxyl components were used in a 1:1.1 molar ratio in order to reduce the amount of secondary products (amines) and to ensure an easier washing of products by using distilled water.

PU structures synthesis procedure was already described in the literature $[12,31]$ and involves the following steps:

1. Phases preparation - HMDI in acetone $0.5 \mathrm{mM}$ solution (organic phase) was heated at $40^{\circ} \mathrm{C}$; MEG, 1,4-BD and PEG 200 (1:1:2, molar ratio) in distilled water $0.5 \mathrm{mM}$ solution (aqueous phase) was mixed with different emulsifiers and heated at $40^{\circ} \mathrm{C}$.

2. The organic phase was injected into the aqueous phase at $40^{\circ} \mathrm{C}$ under magnetic stirring $(500 \mathrm{rpm})$. The stirring was maintained for 4 hours at $40^{\circ} \mathrm{C}$ in

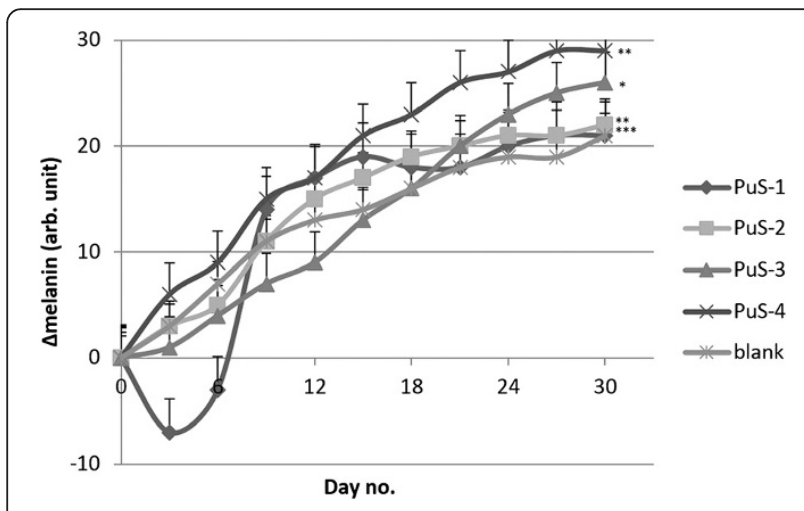

Figure 8 Evolutions of melanin values.

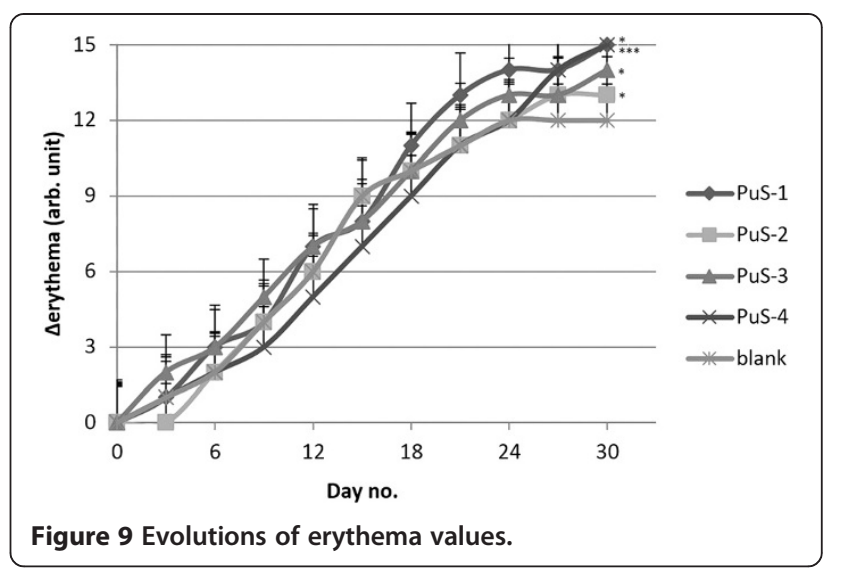

order to ensure the maturation of the PU structures walls, even if the structures were formed in the first three minutes.

3. Acetone and a part of water were removed by slow evaporation in the oven, keeping the suspensions as thin layers (approx. $3 \mathrm{~mm}$ ) in Petri dishes at $60^{\circ} \mathrm{C}$ for 12 hours. Products were purified by three cycles of centrifugation and dispersion in a mixture of water-acetone $(1: 1, \mathrm{v} / \mathrm{v})$ in order to eliminate possible secondary products or unreacted raw materials.

The previously described procedure was repeated four times with different emulsifiers, which were chosen in order to study their effects on the PU characteristics (samples: PuS-1 with Cremophor EL, $1.5 \mathrm{ml}$; PuS-2 with Cremophor A6, 0.2 g; PuS-3 with Cremophor A25, 0.2 g; PuS-4 with Cremophor RH40, $0.2 \mathrm{~g}$ ). The samples were carefully dried and the $\mathrm{pH}$ of $\mathrm{PU}$ aqueous solutions was measured at the same concentration.

\section{Physical and chemical characterization}

The shape and morphology of the final PU structures were examined with a Hitachi 2400 S SEM as already described in the literature [33].

Thermal analysis was carried out using a Mettler-Toledo $821 \mathrm{e}$ instrument between $30-300^{\circ} \mathrm{C}$ because most of the

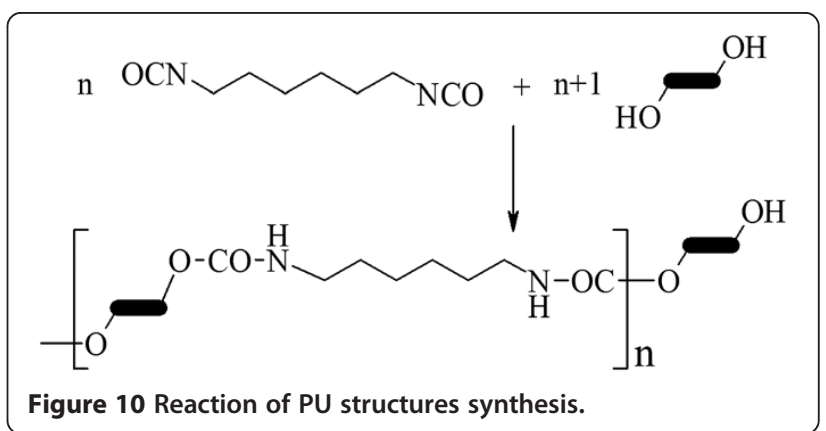


urethane groups (-NH-COO-) are stable in this temperature range [34].

Particles size and charge were measured using a Zetasizer Nano series equipment Nano-Zs, Malvern Instruments. Samples were diluted in distilled water at a ratio of 1:5000 v/v. The measurements were carried out in duplicate for each sample.

In vitro characterization of similar PU structures was already done by our team by testing of mesenchymal stem cells (MSCs) viability. There were obtained good results after 48 hours based on the Alamar Blue test [31].

\section{Animals}

Ten $\mathrm{CD} 1 \mathrm{Nu} / \mathrm{Nu}$ eight weeks old female mice were purchased from Charles River (Sulzfeld, Germany). The protocol followed all National Institute of Animal Health (NIAH) rules: during the experiment animals were maintained in standard conditions of 12 hours light-dark cycle, food and water ad libitum, $24 \pm 1^{\circ} \mathrm{C}$, humidity above $55 \%$. Mice were divided into five equal groups (2 mice for blank cream and each PU structures type, respectively).

\section{Evaluation of skin parameters}

PU structures were included in a cream prepared as previously described in the literature by Pavicic $\mathrm{T}$ et al. [35] in order to observe how they affect skin parameters. The blank cream used was an oil-in-water emulsion containing water, hydrogenated polydecene, steareth-2, cetearyl alcohol, phenoxyethanol, methylparaben, diazolidinyl urea and disodium EDTA; the other formulations contain the same ingredients and additionally $0.2 \%$ PU structures. The cream was stretched with a gentle massage till it was totally absorbed into the back skin every third day $(1 \mathrm{ml} /$ application).

After each application, determination of skin parameters was performed within 30 minutes. All the measurements were carried out according to the published guidelines [36] with a Multiprobe Adapter System (MPA5) from Courage\&Khazaka Electronics, Germany, equipped with a Tewameter ${ }^{\circledR}$ TM300 probe and a Mexameter ${ }^{\circledR}$ MX18 probe. All measurements were done at the same moment of the day, by the same operator, in a narrow range of temperature $\left(24 \pm 1^{\circ} \mathrm{C}\right)$ and air humidity $(45 \pm 3 \%)$.

The nude mice have been used in many studies in immunology, pathology, genetics, virology, parasitology, endocrinology, dermatology, radiology and many other areas [37]. Nude mice are not bald but instead show an 'abortive' reduced hair growth on different sites of the integument [38]. In this research, $\mathrm{CD} 1 \mathrm{Nu} / \mathrm{Nu}$ female mice skin was chosen to study newly synthesized PU structures' noxiousness; their skin is sensitive to experimentally induced infections or to other diseases, the lack of hair being the most significant predisposing factor [39].
Skin is the soft outer layer of humans and most animals. The skin plays a crucial role in protecting the body against pathogens [40]. Another main role is the function as a barrier to water permeation, a phenomenon of normal transfer of water through the stratum corneum into the atmosphere, known as transepidermal water loss (TEWL), which represents part of insensible water loss [41]. TEWL may increase due to disruption of the skin barrier (wounds, scratches, burns, exposure to solvents or surfactants, extreme dryness) and is affected by humidity, temperature, season and moisture content of the skin (hydration level) [42].

Transepidermal water loss (TEWL) was reported to predict the irritation potential of a given compound, e.g. a notable increase of TEWL, meaning a significant reduction of the skin barrier function, was recorded when sodium laurylsulfate (SLS) was applied on the skin [43]. In the last years, TEWL studies focused on the benefits of phytocompounds used in cosmetology [44] and of the antiaging skin products [45]. In this research, the measurements with Tewameter ${ }^{\circledR}$ TM300 probe were accomplished following a procedure previously described in the literature [46]: the probe was recalibrated in the first day of the trial according to the manufacturer's indications [47] while room humidity and temperature were continuously monitored and kept in a narrow range of values.

Mexametry is an easy, quick and inexpensive technique used to determine the two components mainly responsible for the colour of the skin: melanin and haemoglobin (erythema) [48]. In this study, a Mexameter ${ }^{\circledR}$ MX18 probe with three light-emitting diodes for green, red and infrared light was used. Instrumental evaluations of skin colour were performed after each cream application (every third day). The probe was maintained on the application spot until the device software displayed the measured values on the computer screen (1-3 seconds).

All measurements using the Courage\&Khazaka MPA5 device were done in triplicate and data were expressed as mean and standard deviation of the differences between the current day and the first day of the trial for the same mouse.

Paired Student's $\mathrm{t}$ tests or One-way Anova followed by Bonferroni's post-tests were used to determine the statistical difference between different experimental and blank groups: *, ** and *** indicate $\mathrm{p}<0.05, \mathrm{p}<0.01$ and $<0.001$.

\section{Competing interests}

This work was financial supported by The National Research Council from Romania (UEFISCDI): research project PNII-PD-586/2010 (contract no. 110 / 12.08.2010).

\section{Authors' contributions}

CMS, DD and FB have synthesized and purified the PU structures. RA has carried out SEM and DSC analyses. AH, AS, DM, DI and AG have conceived the study, and participated in its design and coordination and helped to draft the manuscript. All authors have read and approved the final manuscript. 


\section{Acknowledgements}

We would like to thank to Srinivas Ganta and Mansoor M Amiji from the Department of Pharmaceutical Sciences (Northeastern University, Boston, US) for the measurement of particle size and charge.

\section{Author details}

${ }^{1}$ Faculty of Pharmacy, "Victor Babes", University of Medicine and Pharmacy Timisoara, 2nd E. Murgu Sq, Timisoara 300041, Romania. ${ }^{2}$ Faculty of General Medicine, Pharmacy and Dental Medicine, "Vasile Goldis" University, 1st Feleacului Str, Arad 310396, Romania. ${ }^{3}$ Department of Pharmaceutical Technology, University of Szeged, 6th Eotvos Str, Szeged H-6720, Hungary. ${ }^{4}$ Faculty of Medicine, "Victor Babes" University of Medicine and Pharmacy Timisoara, 2nd E. Murgu Sq, Timisoara 300041, Romania. ${ }^{5}$ Faculty of Dentistry, "Victor Babes" University of Medicine and Pharmacy Timisoara, 14th T. Vladimirescu Str, Timisoara 300173, Romania.

Received: 10 January 2013 Accepted: 1 April 2013 Published: 10 April 2013

\section{References}

1. Torchilin VP: Introduction. Nanocarriers for drug delivery: needs and requirements. In Nanoparticulates As Drug Carriers. Edited by Torchilin VP. London: Imperial College Press; 2006:1-8.

2. Ogu CC, Maxa JL: Drug interactions due to cytochrome P450. Proc (Bayl Univ Med Cent) 2000, 13(4):421-423.

3. Clarke SJ, BC: Human cytochromes P450 and their role in metabolism-based drug-drug interactions. In Drug-drug interactions. New York: Marcel Dekker, Inc; 2002:55-88.

4. Pachence JM, Simon P: Novel methods for site-directed drug delivery. Drug Delivery Technol 2003, 3(1):40.

5. Vauquelin G, Charlton SJ: Long-lasting target binding and rebinding as mechanisms to prolong in vivo drug action. Br J Pharmacol 2010, 161(3):488-508.

6. Wright J: Using Polyurethanes in Medical Applications. Medical Device \& Diagnostic Industry 2006, 28(3):98-109.

7. Sivak WN: Synthesis and Characterization of Novel Polyurethane Drug Delivery Systems. Doctoral Dissertation: University of Pittsburgh; 2007.

8. Sivak WN, Pollack IF, Petoud S, Zamboni WC, Zhang J, Beckman EJ: Catalyst-dependent drug loading of LDI-glycerol polyurethane foams leads to differing controlled release profiles. Acta Biomater 2008, 4(5):1263-1274

9. Kim D, Kim E, Lee J, Hong S, Sung W, Lim N, Park CG, Kim K: Direct synthesis of polymer nanocapsules: self-assembly of polymer hollow spheres through irreversible covalent bond formation. J Am Chem Soc 2010, 132(28):9908-9919.

10. Liu X, Basu A: Core functionalization of hollow polymer nanocapsules. J Am Chem Soc 2009, 131(16):5718-5719.

11. Polyurethanes types. http://www.merquinsa.com/whats/FPPUtypes1.pdf.

12. Bouchemal K, Briancon S, Perrier E, Fessi H, Bonnet I, Zydowick N: Synthesis and characterization of polyurethane and poly(ether urethane) nanocapsules using a new technique of interfacial polycondensation combined to spontaneous emulsification. Int J Pharm 2004, 269:89-100.

13. Redes L, Borcan F, Lonescu D, Ambrus R, Galuscan A, Popovici l: Synthesis and characterization of a polyurethane transdermal carrier for lupeol. J Agroaliment Process Technol 2011, 17(3):321-325.

14. Ehlers C, Ivens UI, Møller ML, Senderovitz T, Serup J: Females have lower skin surface $\mathrm{pH}$ than men. A study on the surface of gender, forearm site variation, right/left difference and time of the day on the skin surface pH. Skin Res Technol 2001, 7(2):90-94

15. Lambers $H$, Piessens $S$, Bloem A, Pronk $H$, Finkel $P$ : Natural skin surface $\mathrm{pH}$ is on average below 5 , which is beneficial for its resident flora. Int J Cosmet Sci 2006, 28(5):359-370.

16. Gallardo V, Morales ME, Ruiz MA, Delgado AV: An experimental investigation of the stability of ethylcellulose latex. Correlation between zeta potential and sedimentation. Eur J Pharm Sci 2005, 26:170-175.

17. Champion JA, Katare YK, Mitragotri S: Particle shape: A new design parameter for micro- and nanoscale drug delivery carriers. J Control Release 2007, 121:3-9.
18. Zhang XD, Macosko CW, Davis HT, Nikolov AD, Wasan DT: Role of Silicone Surfactant in Flexible Polyurethane Foam. J. Coll. Interface Sci. 1999, 215:270-279.

19. Differential Scanning Calorimetry - Science @ Stanislaus. http://science. csustan.edu/perona/4012/dsc_exp.pdf.

20. Royall PG, Craig DQM, Doherty C: Characterisation of the Glass Transition of an Amorphous Drug Using Modulated DSC. Pharm Res 1998, 15:1117-1121.

21. Hentschel T, Munstedt $\mathrm{H}$ : Kinetics of the molar mass decrease in a polyurethane melt: a rheological study. Polymer 2001, 42:3195-3203.

22. Tanriverdi F, Borlu M, Atmaca H, Koc CA, Unluhizarci K, Utas S, Kelestimur F: Investigation of the skin characteristics in patients with severe GH deficiency and the effects of 6 months of $\mathrm{GH}$ replacement therapy: a randomized placebo controlled study. Clin Endocrinol 2006, 65:579-585.

23. Agar N, Young AR: Melanogenesis: a photoprotective response to DNA damage? Mutat Res 2005, 571(1-2):121-132.

24. Atlas SW, Braffman BH, LoBrutto R, Elder DE, Herlyn D: Human malignant melanomas with varying degrees of melanin content in nude mice: MR imaging, histopathology, and electron paramagnetic resonance. J Comput Assist Tomogr 1990, 14(4):547-554.

25. Dadachova E, Revskaya E, Sesay MA, Damania H, Boucher R, Sellers RS, Howell RC, Burns L, Thornton GB, Natarajan A, Mirick GR, DeNardo SJ, DeNardo GL, Casadevall A: Pre-clinical evaluation and efficacy studies of a melanin-binding lgM antibody labeled with 188Re against experimental human metastatic melanoma in nude mice. Cancer Biol Ther 2008, 7(7):1116-1127.

26. Curtis A, Calabro K, Galarneau JR, Bigio IJ, Krucker T: Temporal Variations of Skin Pigmentation in C57BI/6 Mice Affect Optical Bioluminescence Quantitation. Mol Imaging Biol 2011, 13(6):1114-1123.

27. Costin $G E$, Hearing VJ: Human skin pigmentation: melanocytes modulate skin color in response to stress. FASEB J 2007, 21(4):976-994.

28. The American Heritage medical dictionary, Editors of the American Heritage Dictionaries: Boston, MA: Houghton Mifflin Harcourt.

29. Wilhelm KP, Freitag G, Wolff HH: Surfactant-induced skin irritation and skin repair. Evaluation of the acute human irritation model by noninvasive techniques. J Am Acad Dermatol 1994, 30(6):944-949.

30. Borcan F, Dehelean CA, Anghel A: Obtaining and Characterization of Polyether-Urethane Nanostructures - A Possible Drug Carrier System. Ann. West Univ. Timisoara, Series Chem 2011, 20(1):41-46.

31. Borcan F, Soica CM, Ganta S, Amiji MM, Dehelean CA, Munteanu MF: Synthesis and preliminary in vivo evaluations of polyurethane microstructures for transdermal drug delivery. Chem Cent J 2012, 6(1):87.

32. Borcan F, Soica CM, Dehelean CA, Ganta S, Amiji MM: Size and Stability Optimization for Polyurethane Nanostructures used as Transdermal Drug Vehicle. Rev. Chim. Bucharest 2012, 63(11):1164-1166.

33. Soica CM, Peev Cl, Ciurlea S, Ambrus R, Dehelean CA: Physico-chemical and toxicological evaluations of betulin and betulinic acid interactions with hydrophilic cyclodextrins. Farmacia 2010, 58(5):611-619.

34. Simon J, Barla F, Kelemen-Haller A, Farkas F, Kraxner M: Thermal stability of polyurethanes. Chromatographia 1988, 25(2):99-106.

35. Pavicic T, Gauglitz GG, Lersch P, Schwach-Abdellaoui K, Malle B, Korting HC, Farwick M: Efficacy of Cream-Based Novel Formulations of Hyaluronic Acid of Different Molecular Weights in Anti-Wrinkle Treatment. J Drugs Dermatol 2011, 10(9):990-1000.

36. Rogiers $V$, EEMCO Group: EEMCO guidance for the assessment of transepidermal water loss in cosmetic sciences. Skin Pharmacol App/ Skin Physiol 2001, 14(2):117-128.

37. Sharkey FE, Fogh J: Considerations in the use of nude mice for cancer research. Cancer Metastasis Rev 1984, 3:341-360.

38. Militzer K: Hair growth pattern in nude mice. Cells Tissues Organs 2001, 168(4): 285-294.

39. Fox JG, Barthold SW, Davisson MT, Newcomer CE, Quimby FW, Smith AL: The Mouse in Biomedical Research. 2nd edition. Burlington MA: Academic Press; 2006.

40. Proksch E, Brandner JM, Jensen JM: The skin: an indispensable barrier. Exp Dermatol 2008, 17(12):1063-1072.

41. Madison KC: Barrier function of the skin: "la raison d'être" of the epidermis. J Invest Dermatol 2003, 121(2):231-241.

42. Chemistry of skin: Trans-epidermal water loss (TEWL). http://swiftcraftymonkey. blogspot.ro/2010/03/chemistry-of-skin-trans-epidermal-water.html.

43. Antoine $J$, Contreras $J$, van Neste D: ph Influence on surfactant-induced skin irritation. Dermatosen in Beruf und Umwelt 1989, 37(3):96-100. 
44. Dell'Acqua G, Schweikert K, Calloni G: Oak, Green Tea and Orange Derivatives to Disrupt JAK/STAT, NF-kB Irritation Pathways. Cosmetics \& Toiletries 2011, 126(1):30-39.

45. Thibodeau A: Anti-aging Skin Care Benefits of Saccharina longicruris Extract. Cosmetics \& Toiletries 2011, 126(3):208-216.

46. Mündleina M, Valentina B, Chabicovskya R, Nicolicsa J, Weremczukb t, Tarapatab G, Jachowicz R: Comparison of transepidermal water loss (TEWL) measurements with two novel sensors based on different sensing principles. Sensors and Actuators A: Physical 2008, 142(1):67-72.

47. MPA5-TM300 Manual. http://www.courage-khazaka.de.

48. MPA5-MX18 Manual. http://www.courage-khazaka.de.

\section{doi:10.1186/1752-153X-7-66}

Cite this article as: Heghes et al:: Influence of emulsifiers on the

characteristics of polyurethane structures used as drug carrier. Chemistry Central Journal 2013 7:66.

\section{Publish with ChemistryCentral and every scientist can read your work free of charge \\ "Open access provides opportunities to our colleagues in other parts of the globe, by allowing anyone to view the content free of charge." \\ W. Jeffery Hurst, The Hershey Company. \\ - available free of charge to the entire scientific community \\ - peer reviewed and published immediately upon acceptance \\ - cited in PubMed and archived on PubMed Central \\ - yours - you keep the copyright \\ Submit your manuscript here: \\ http://www.chemistrycentral.com/manuscript/<smiles>c1ccccc1</smiles> 